Bilingualism: Language and Cognition

http://journals.cambridge.org/BIL

Additional services for Bilingualism: Language and Cognition:

Email alerts: $\underline{\text { Click here }}$

Subscriptions: $\underline{\text { Click here }}$

Commercial reprints: Click here

Terms of use : $\underline{\text { Click here }}$

\title{
Neurolinguistic evidence for bilingual language representation: a comparison of reaction times and event-related brain potentials
}

\author{
Sonja A. Kotz
}

Bilingualism: Language and Cognition / Volume 4 / Issue 02 / August 2001, pp 143 - 154

DOI: 10.1017/S1366728901000244, Published online: 13 August 2001

Link to this article: http://journals.cambridge.org/abstract_S1366728901000244

How to cite this article:

Sonja A. Kotz (2001). Neurolinguistic evidence for bilingual language representation: a comparison of reaction times and eventrelated brain potentials. Bilingualism: Language and Cognition, 4, pp 143-154 doi:10.1017/S1366728901000244

Request Permissions : $\underline{\text { Click here }}$ 


\title{
Neurolinguistic evidence for bilingual language representation: a comparison of reaction times and event- related brain potentials*
}

SONJA A. KOTZ

Max Planck Institute of Cognitive Neuroscience, Leipzig

\begin{abstract}
The current study set out to examine word recognition in early fluent Spanish-English bilinguals using a single word presentation lexical decision task (LDT). Reaction times ( RTs) and event-related brain potentials (ERPS) were measured while subjects (16 per language condition) made a lexical decision on words and pseudowords in either Spanish or English. Results show associative priming as measured by RTs, but both associative and categorical priming in the ERPs in both language conditions. The dissociation of RT and ERP effects suggests that the two measures might tap into different underlying processes during semantic priming or reflect different sensitivities towards semantic priming. Furthermore, both RT and ERP measures revealed symmetrical priming in L1 and L2. These data indicate that word recognition in early fluent bilinguals is equivalent for L1 and L2.
\end{abstract}

In order to understand how a bilingual speaker uses and comprehends two languages, it is necessary to explain how different types of linguistic knowledge such as lexical-semantic information in both languages are accessed, stored and maintained. A central question that arises is whether the representation of linguistic knowledge in each language is stored in a separate memory system or in a common memory system. Current bilingual information processing models such as the hierarchical model (Potter, So, von Eckhardt and Feldman, 1984; Snodgrass, 1984) and the revised hierarchical model (Kroll and Stewart, 1990 ; 1994) suggest that bilingual language representation concerns the mapping of form to meaning. This implies two levels of representation, namely a lexical level and a conceptual level of representation. The basic assumption of both hierarchical models is that word form is represented separately in L1 and L2 (see Gerard and Scarborough, 1989), while word meaning is represented in a common conceptual system for both languages (see Durgunoglu and Roediger, 1987).

Furthermore, the hierarchical models assume that the interaction between the two lexical level represen-

\footnotetext{
* The author wishes to thank Phillip J. Holcomb and Judith Kroll for their support and guidance while the current experiment was conducted as part of the author's dissertation. Special thanks to Angela D. Friederici and Trevor Penney for helpful comments on an earlier version of the paper.
}

tations and between the lexical level representations and the conceptual representation varies as a function of L2 fluency. This means that during L2 language acquisition the learner will access L2 words via the L1 lexicon. With increasing L2 fluency access via L1 will be reduced and direct conceptual processing in L2 is possible. However, since the models assume that the enhanced access to meaning via $\mathrm{L} 1$ strengthens the route between the L1 lexicon and the conceptual level there will always be language asymmetry. Nevertheless, these language asymmetries could be altered by relative language dominance (Heredia, 1997), maturational constraints (WeberFox and Neville, 1996) or the fact that individuals who acquire both languages early may acquire and use words from both languages at the same time and may link these to developing conceptual representations (Kotz, 1996).

To test the nature of the connections between the two levels of representation both forward and backward translation tasks (e.g., De Groot, 1992; Kroll, 1993) and the primed lexical decision task (LDT; e.g., Meyer and Schvaneveldt, 1971; Neely, 1991) have been used in fluent and less fluent bilinguals. In monolinguals, the response to a target word is faster when it is preceded by a semantically related prime word rather than a semantically unrelated prime word. So the word $d o g$ is processed faster if it is preceded by the word cat than by the word table.

Address for correspondence

Sonja A. Kotz, Max-Planck-Institute of Cognitive Neuroscience, Stephanstrasse 1a, P.O. Box 500355, D-04303 Leipzig, Germany

E-mail:kotz@cns.mpg.de 
Semantic priming is also a tool to test how bilinguals activate L2 words conceptually. If word concepts are shared between languages there should be equal semantic priming in L1 and L2 in fluent bilinguals, while there should be asymmetrical priming in L1 and L2 when the bilingual is less fluent.

Several bilingual studies utilized the lexical decision task to explore the nature of semantic priming within L1 and L2. Reports of comparable semantic priming effects in L1 and L2 (Chen and $\mathrm{Ng}, 1989$; Jin, 1990; Frenck-Mestre and Pynte, 1987; FrenckMestre and Prince, 1997; Kirsner, Smith, Lockhardt, King and Jain, 1984; Meyer and Ruddy, 1974; Schwanenflugel and Rey, 1986; Tzelgov and Henik, 1989; Williams, 1994) have been criticized on the grounds that subjects either process target words by checking the prime-target relationship or translate the L2 target into L1 (e.g., Altarriba, 1990). Thus, symmetrical semantic priming in L1 and L2 might be the result of controlled processes rather than automatic processes (see Neely, 1991). In numerous monolingual behavioral (De Groot, 1984; Den Heyer, Briand and Dannenberg, 1983; Neely, 1991) and electrophysiological (ERPs) studies (Anderson and Holcomb, 1995; Boddy, 1986; Holcomb, 1986, 1988) as well as in bilingual behavioral studies (Altarriba, 1991; Keatley and De Gelder, 1992; Keatley, Spinks and De Gelder, 1994; Kroll, Sholl, Altarriba, Luppino, Moynihan and Sanders, 1992; Tzelgov and Eben-Ezra, 1992) it has been argued that the use of a high proportion of related targets and long stimulus onset asynchronies (SOAs) raises the likelihood that subjects will predict the target from the prime (see also Becker, 1979, 1980). By decreasing the proportion of related targets ${ }^{1}$ and shortening the SOA, conscious recognition of prime and target pairs can be reduced and automatic aspects of priming can be achieved in both measures (but see De Groot, 1984). As a consequence, bilingual studies that induced automatic semantic priming mainly reported asymmetrical semantic priming effects comparing L1 and L2 (Altarriba, 1990, 1991; De Groot and Nas, 1991 (non-cognates); Gerard and Scarborough, 1989; Beauvillain and Grainger, 1988; Keatley et al., 1994; Larsen, Fritsch and Grava, 1994; Scarborough, Gerard and Cortese 1984, Experiment 2). These latter results are in support of the revised hierarchical model (Kroll and Stewart, 1990). However, it has been critically noted (Snodgrass, 1993) that the use of RTs might not suffice to monitor the effect of change in language fluency on the different processing stages

\footnotetext{
1 The proportion effect implies that priming for related items increases if there is a high proportion of related as compared to unrelated items in an experimental condition.
}

during word recognition. Therefore, explanations about the precise nature of the underlying process(es) of bilingual word recognition remain speculative.

The application of an on-line measure such as ERPs might permit a more precise evaluation of process(es) underlying bilingual word recognition as a function of L2 fluency. RTs are measured at discrete points in time, which makes it difficult to identify and interpret how specific processes could have contributed to an effect. On the other hand, ERPs, which measure on-going electrical brain activity, can measure multidimensional data points from latency, amplitude, polarity, and scalp distribution of a component (a series of valleys and peaks in the EEG) under investigation. More specifically, given its high temporal resolution, ERPs can (in theory) measure a process(es) on-line, as it unfolds.

Semantic priming is also reflected in the N400 component of the ERP during word and sentence processing (see Anderson and Holcomb, 1995; Van Petten and Kutas, 1990). In general, greater degrees of semantic discrepancy elicit a larger negative amplitude about $400 \mathrm{~ms}$ after the onset of a target word. One process which might be underlying this effect is post-lexical integration (e.g., Holcomb, 1993). However, results from ERP LDT studies indicate that the N400 effect might not just reflect post-lexical integration, but also automatic processes (i.e., automatic spread of activation; Neely, 1991). For example, the N400 was reported in short and long SOA conditions during semantic priming (e.g., Anderson and Holcomb, 1995; Boddy, 1986). Since the N400 priming effect at a short SOA was too short for post-lexical integration to take place it has been argued that the N400 reflects both post-lexical integration and automatic spread of activation (e.g., Besson, Kutas and Van Petten, 1992; Deacon, Hewitt, Yang and Nagata, 2000, Holcomb, 1988, but see for counter-evidence Brown and Hagoort, 1993; Chwilla, Brown and Hagoort, 1995; Chwilla, Kolk and Mulder, 2000).

To shed more light on the cognitive mechanisms underlying the N400, Kotz and Holcomb (1996) and Kotz (1998) utilized the single word presentation LDT combined with different types of semantic relations (associative vs. categorical; see Table 1) in a visual and auditory RT/ERP experiment. The advantage of the single word presentation LDT is that prime and target words are presented in a list rather than as pairs and subjects make a lexical decision on all words and pseudowords. It is assumed that such a presentation decreases controlled processing of prime/ target pairs (see Shelton and Martin, 1992) and therefore induces automatic semantic priming. Furthermore, behavioral studies that explored the nature of 
semantic priming have proposed that the type of semantic relation (i.e., associative vs. categorical) might lead to differential priming effects (Moss, Ostrin, Tyler and Marslen-Wilson,1995; Shelton and Martin, 1992; but see McRae and Boisvert, 1998). Thus, automatic priming of associative relations that are linked by co-occurrence frequency might reflect the spread of activation in the lexical network (see Lupker, 1984), while priming of words that share semantic features/properties (category exemplars) might result from controlled processes such as postlexical integration (Forster, 1979; Kroll et al., 1992; Shelton and Martin, 1992).

The principal aim of the single word presentation LDT ERP study by Kotz and Holcomb (1996) was to determine whether one can substantiate automatic semantic priming in the N400 component. It was predicted that if RTs and ERPs were equally sensitive to automatic processes only associative targets should elicit RT and N400 priming effects. Behavioral findings in both modalities replicated the data reported by Shelton and Martin (1992) - there was associative, but no categorical priming. In comparison, the ERP data revealed associative and categorical N400 priming. Consequently, the RT data provide evidence for automatic associative priming. However, there were higher error rates and slower response rates to categorically related targets. It has been argued elsewhere that categorical priming often results in a smaller and more variable effect (e.g., Dagenbach, Horst and Carr, 1990; Shelton and Martin, 1992). Thus, one drawback of the RT measure might be that it is less susceptible to this variability (see also Snodgrass, 1993). Following this logic, the different pattern of RT and ERP semantic priming might be due to ERPs being more sensitive to smaller priming effects. Thus, as RT and ERP measures might provide different sensitivities in terms of semantic priming, a comparison of the two measures should provide clarifying evidence as to how language fluency affects bilingual word recognition.

\section{The current experiment}

We set out to evaluate the time-course of bilingual word recognition utilizing both RTs and ERPs in a single word presentation LDT priming paradigm. The basic rationale was to prevent subjects from using strategies such as predicting the target from the prime before making a lexical decision. Furthermore, we used different types of semantic relations to explore differential priming effects. Lastly, we tested early fluent bilingual speakers of Spanish and English to find out whether early language acquisition of L2 modulates language asymmetry and if so whether we see any on-line realization of the effect in the ERP. Based on the revised hierarchical model and the monolingual ERP data the following predictions were made.

If fluent bilinguals access conceptual representations equally fast and efficiently in L1 and L2 then there should be a comparable result in both language conditions to monolingual speakers, namely, associative RT priming and ERP associative and categorical priming in the single word presentation LDT. However, if early acquisition of L2 still results in concept mediation of L2 via L1, then the RT and ERP priming effects in L1 should be comparable to those of monolingual speakers but the effects in L2 should be smaller.

\section{Method}

\section{Subjects}

Thirty-two undergraduate students at Tufts University volunteered to participate in the experiment. Some subjects participated for partial course credit, while others were paid $\$ 15$ each. Sixteen subjects each were randomly assigned to two language conditions: L1 (Spanish) and L2 (English). All participants were native speakers of Spanish with near native knowledge of English. All subjects had started to acquire English before the age of four in an informal setting (home, day care). At the time of the experiment, all subjects resided in the US. The average age of subjects (6 males) was 19.8 years (s.d. $=3.2$ ) in L1 and in L2 (7 males) 19.5 years (s.d. = 1.8). All subjects were right-handed and had normal or corrected-to-normal vision.

\section{Design}

In a mixed factor design Language ${ }^{2}$ (Spanish/ English) was the between-subjects factor and Relatedness (related/unrelated) and Semantic relation (associative/categorical) were the within-subjects factors.

\section{Materials}

Selection of Stimuli. Associated prime words for the English version were selected from a word association norming task with 54 subjects who generated up to three word associations for each of 180 given target words (normative word frequency $=59.6$ ). Subjects were asked to proceed as fast as possible

\footnotetext{
2 The choice of a between-subjects design was necessary due to the limited number of stimuli.
} 
without revising or rethinking their word generation choices. The first association chosen by most subjects (cut off: $80 \%$ ) was selected as a prime word and cross-checked with word association norms (Postman and Keppel, 1970). Categorical primes were always exemplars of the same category as the target item (see also Shelton and Martin, 1992). The normative word frequency (Kucera and Francis, 1967) for the generated associative primes $(\mathrm{M}=66.3)$ was higher than the normative word frequency of categorical primes $(\mathrm{M}=30.3 ; t[381]=301, p<.01)$. Selected categorical primes that were generated as an associative prime were replaced by a categorical exemplar of equal normative word frequency. Mean length of both prime and target words was balanced across semantic relations. The average word length was 5.5 letters (range: 3 to 9 letters). All words were concrete nouns.

In a second norming study, 12 native English speakers (6 females) rated the degree of semantic relatedness of 320 categorical and associative word pairs (160 word pairs per semantic relation) and 160 unrelated word pairs on a five-point scale $(0=$ not at all related, $5=$ highly related). Unrelated word pairs were created from related pairs so that there was no semantic relation between primes and targets. No target (related or unrelated) was repeated. The mean relatedness rating of associative word pairs $(\mathrm{M}=$ 3.32) was slightly higher than that for categorical word pairs $(\mathrm{M}=3.03 ; t[159]=1.94, p=.053)$. Both associative $(t[159]=40.98, p<.01)$ and categorical word pairs $(t[159]=48.92, p<.01)$ were rated significantly more related than the unrelated word pairs $(M=1.08)$.

Items for the Spanish version were translated from English into Spanish (Harper Collins, 1990). English words were matched with their primary translation equivalent in Spanish. A group of native Spanish speakers evaluated the Spanish translations for appropriate translation meaning and correct spelling. One speaker each from Spain, Puerto Rico, Mexico, Costa Rica, Argentina and Venezuela rated the Spanish word material for meaning discrepancies that can result from the differential use of words in Spanish speaking countries. However, there was almost no discrepancy between the rating of these Spanish speakers, so no critical items needed to be eliminated from the experimental list. Lists in English and Spanish therefore were of comparable length. Associative relations were then checked against Spanish word association norms (Algarbel, Ruiz and Sanmartin, 1988) to confirm that comparable associations in Spanish and English were established. As in the English version, categorical items that occurred as associates to Spanish associative targets were eliminated.
Table 1. Examples of the material used in each experimental condition in L1 (Spanish) and L2 (English)

\begin{tabular}{llllll}
\hline \hline & \multicolumn{2}{c}{ English } & & \multicolumn{2}{c}{ Spanish } \\
\cline { 2 - 3 } \cline { 5 - 6 } Semantic Relation & Prime & Target & & Prime & Target \\
\hline Associatively Related & Girl & Boy & & Chica & Chico \\
Associatively Unrelated & House & Boy & & Casa & Chico \\
Categorically Related & Junior & Boy & & Joven & Chico \\
Categorically Unrelated & Pond & Boy & & Lago & Chico \\
Word/Pseudoword & Jet & Flark & & Chorro & Podel \\
\hline \hline
\end{tabular}

Word length was matched as closely as possible in the Spanish word list. While words in the English condition varied between 2 and 9 letters, words in the Spanish list had between 3 and 12 letters. An attempt was made to match English and Spanish prime (across semantic relations) and target word frequency. Given the high number of words in this experiment (400 real words and 240 pseudowords), the only available frequency index in Spanish was not comprehensive enough to ensure word frequency control (Juilland and Chang-Rodriguez, 1964).

Spanish pseudowords were taken from a list of pseudowords that had previously been used in Spanish priming studies (Perea and Carreiras, 1998). Pseudowords were created according to the same principles as the pseudowords in the English version. One letter of a Spanish word was changed to form a pseudoword. The letter change was either at the beginning, the middle or the end of a real word in Spanish. The number of letter position changes was the same across all pseudowords. Pseudowords adhered to the phonological and orthographical rules of Spanish.

In summary, words were counterbalanced across four lists in L1 and L2, respectively. Each subject saw each word once, but between subjects each word was presented an equal number of times in each of the four conditions (associatively related, associatively unrelated, categorically related, categorically unrelated). This scheme ensured that in the grand average ERPs the comparison across target conditions were for the same items.

\section{Procedure}

Behavioral evaluation. All bilingual subjects participated in a word naming task of an English and a Spanish list. Two English and two Spanish lists were created (40 items each). Items in the list were concrete nouns (e.g., platter) and verbs (e.g., push). Average 
word length was 5 letters in L1 and 6 letters in L2. Normative word frequency was 60.2 in English. Subjects were presented with a list both in L1 and in L2 (counterbalanced) and were instructed to read words aloud at their normal reading speed. Global reaction time was measured for each list. This measure was utilized to control for comparable fluency in Spanish and English. After subjects finished the ERP experiment they filled out an extensive language questionnaire which included information about their language history and language fluency. The questionnaire was administered after the experiment to prevent subjects from anticipating the experimental parameters. The total time of participation was two hours.

$R T$ and ERP experiment. Subjects first saw a training list of 180 items (56 pseudowords) created for each language condition. This list was not part of the experimental trial run. However, items were matched for critical parameters of the items in the experimental lists (concrete nouns, word length, word frequency, category membership and associativeness). After that subjects viewed either a list of 640 test items (relatedness proportion across semantic relations: .20; pseudoword proportion: .37) in English or Spanish. They were instructed to respond with "YES/SI" to each word in English or Spanish and with "NO/NO" to each pseudoword in English or Spanish. Response labels were counterbalanced along with response handedness (right vs. left). The language of instruction was English and Spanish, respectively.

ERP recording procedure. Subjects sat in a comfortable chair which was located in a sound-attenuating chamber. An elastic cap (Electrode-Cap international) with tin electrodes was placed on their head. Scalp locations included standard International 10-20 systems locations (Jasper, 1958) over the left and right hemispheres at frontal (F7, F8), occipital $(\mathrm{O} 1, \mathrm{O} 2)$ and three midline locations: frontal $(\mathrm{Fz})$, central $(\mathrm{Cz})$ and parietal $(\mathrm{Pz})$. Electrodes were also placed at six non-standard locations over left (WL) and right (WR) temporo-parietal cortex $(30 \%$ of the interaural distance lateral to a point $13 \%$ of the nasion-inion distance posterior to $\mathrm{Cz}$ ), left (TL) and right (TR) temporal cortex $(33 \%$ of the interaural distance to $\mathrm{Cz}$ ) and left (ATL) and right (ATR) anterior-temporal cortex $(50 \%$ of the distance between T3/4 and F7/8). These sites have previously been found sensitive to language manipulations (Holcomb and Neville, 1990, 1991). Two additional electrodes were placed below the left eye to monitor for eye blinks and lateral to the right eye to record horizontal eye movements. Trials with eye blinks and movement artifacts were removed from the raw data set prior to single subject averaging by setting a rejection threshold of $30 \mu \mathrm{V}$ for the two eye channels and $20 \mu \mathrm{V}$ for Fz. All electrodes were referenced to the left mastoid.

Each EEG channel was amplified with a bandpass of 0.01 to $100 \mathrm{~Hz}$ at a $3 \mathrm{db}$ cutoff. The EEG was recorded continuously and stored for later analysis at a sampling rate of $200 \mathrm{~Hz}$; separate ERPs were averaged (100 ms pre-stimulus baseline) for each subject at each electrode site. Throughout the experiment, subjects were given a break of approximately one minute after 60 to 80 trials to control for eye movements.

Stimuli were presented on a CRT (20 inch monitor, NEC 5D) word by word as black lower case letters on a white background. Each word subtended from .5 to 1.8 degrees of horizontal and .4 degrees of vertical visual angle. Each trial began with a fixation cross in the middle of the screen for $1000 \mathrm{~ms}$ to indicate the start of the experiment. Subsequently, a word was presented at the center of the screen for 450 $\mathrm{ms}$. The inter-stimulus-interval was $575 \mathrm{~ms}$. The overall SOA was $1025 \mathrm{~ms}$ (see also Shelton and Martin, 1992). Latency jitter was not introduced during the inter-stimulus-interval.

$R T$ and ERP data analyses. Mean RTs and percentage errors were calculated for each subject (Time window: 200-1025 ms for correct responses). The critical language comparisons of the ERP data were quantified for correct responses by calculating mean amplitudes relative to a $100 \mathrm{~ms}$ pre-stimulus baseline in three latency windows $(150-300 \mathrm{~ms}, 300-550 \mathrm{~ms}$, and $550-800 \mathrm{~ms}$ ). The first two time windows were chosen because they correspond to the time window of the P2 and the N400 (see Anderson and Holcomb, 1995; Holcomb, 1988; Holcomb and Neville, 1990; 1991; Kotz and Holcomb, 1996). The later time window is a latency range typically ascribed to the P300 which is correlated with stimulus evaluation and classification (e.g., Kutas, McCarthy and Donchin, 1979). Analyses of variance for repeated measures (ANOVAs) with two levels of Semantic relation (associative vs. semantic) and two levels of Relatedness (related/unrelated) and Language (L1/L2) as the between-subjects factor were performed. ANOVAs for midline and lateral sites were run separately. The midline site analysis included an additional factor Electrode-Site (Fz vs. Cz. vs. Pz) and the lateral site analysis involved Electrode-Site (Frontal vs. Anterior Temporal vs. Temporal vs. Wernicke's vs. Occipital) and Hemisphere (left vs. right). Significant main effects and interactions were followed up by simple effects analyses and pairwise comparisons. The Geisser-Greenhouse correction (Geisser and Greenhouse, 1959) was applied to all 
repeated measures with greater than one degree of freedom. Whenever the comparison of two critical conditions resulted in an interaction with the factor Electrode-Site, a normalization procedure (McCarthy and Wood, 1985) was applied to evaluate topographic differences. Yet, on the basis of such an interaction it cannot be concluded that different neuronal structures are underlying a component simply because the component has a different topographic distribution, since the interaction could be the result of variable activity of one and the same neuronal generator. The normalization procedure proposed by McCarthy and Wood (1985) normalizes the mean values of ERP differences between two conditions relative to the root mean square values across a region of interest and a fixed time window. If normalized data still results in an interaction with the factor Electrode-Site, the result can be interpreted such that different neuronal generators underlie two contrastive ERP components (see also Johnson, 1993). In the ERP result section only normalized data is presented when interactions with the factor Electrode-Site occurred.

\section{Results}

The results section is structured in the following way: first, data from the questionnaire will be presented (subject data), second, the data from the naming task (naming data), third RTs and percentage error for each language condition on the experimental trials will be followed by the ERP data for each Language condition.

Subject data. As noted in the procedure section, each bilingual subject completed a language questionnaire. Responses were compiled and listed as comparisons between the two language conditions (Spanish (L1) and English (L2)). The primary variables of interest were analyzed with an analysis of variance (ANOVA).

Almost all subjects rated Spanish as their native language (L1 condition:15/16 subjects and L2 condition:14/16 subjects). There were subjects in each language condition that perceived both Spanish and English as their native language (L1 condition:1 subject, L2 condition: 2 subjects). Subjects reported that they had spoken Spanish for a greater number of years (about four) than English (L1: $F[1,15]=24.28$, $p<.01$; L2: $F[1,15]=56.79, p<.01)$. Overall, subjects in both language conditions had spent a similar number of years in an English speaking environment $(F[1,30]=1.51, p>.05)$.

Fluency ratings in Spanish and English indicated that subjects rated their fluency in both languages almost similarly $(F[1,30]=2.36, p>.05)$. Respective mean fluency in Spanish and English were in the L1 condition $($ Spanish $=9.19$, s.d. $=0.32 ;$ English $=$ 8.87 , s.d. $=0.27)$ and in the L2 condition (Spanish $=$ 8.75, s.d. $=1.44 ;$ English $=9.43$, s.d. $=0.27$ ). The preferred language for reading was English. Literacy ratings of reading and writing in Spanish and English did result in a marginal differences across languages $(F[1,30]=2.64, p>.05)$ suggesting that the L2 condition literacy was slightly higher than the L1 condition literacy. Both fluency and literacy ratings were based on a ten-point scale $(1=$ not fluent/ literate, $10=$ fluent/literate).

Naming data. A word naming task was conducted before the experiment in order to control for naming fluency in the L1 and L2 conditions. Overall naming RTs in the L2 condition were faster than in the L1 condition $(F[1,30]=18.42, p<.01)$ and differences across language conditions approached significance $(F[1,30]=2.42, p>.05)$. The mean naming latencies in seconds in the L1 condition was (Spanish $=23.86$, s.d. $=1.43$; English $=22.36$, s.d. $=4.58)$ and in the L2 condition $($ Spanish $=28.19$, s.d. $=4.20 ;$ English $=$ 24.22 , s.d. $=4.66) .^{3}$

\section{Reaction times ( $R T)$ percentage error}

In general, subjects responded faster to associative targets than to categorical targets $(F[1,30]=4.31$, $p<.05$; see Table 1). Also, subjects responded faster to related targets than to unrelated targets $(F[1,30]$ $=7.57, p<.01)$. However, there was no significant interaction between the main effect of Semantic relation and the main effect of Relatedness $(F<1)$ nor between the two main effects and the Language condition $(F<1)$. We note though, that the initial hypothesis predicted only associative RT priming (see monolingual RT evidence). Therefore, separate analyses for the factor Semantic relation were applied. The results revealed a significant associative priming effect $(F[1,30]=8.96, p<.01)$, but no categorical priming effect $(F<1)$. This effect was comparable in the L1 and the L2 conditions (i.e., there was no Language effect; $F<1$ ).

A main effect of Language showed that bilinguals in the L1 condition made more errors across all factors (Relatedness and Semantic relation) than bilinguals in the $\mathrm{L} 2$ condition $(F[1,30]=8.49, p<.01)$. This main effect of Language was qualified by an interaction of Language, Relatedness and Semantic

\footnotetext{
${ }^{3}$ It is critical to note that on average naming in Spanish is longer than in English as the overall word length in Spanish is longer than in English. Furthermore, naming a word in Spanish requires pronunciation of every syllable. Thus, RT naming differences in Spanish and English could be due to languageinherent differences.
} 
Table 2. Response times and percentage error (ms; standard deviations) comparing bilinguals in L2 and L1 in the single word presentation $L D T$

\begin{tabular}{|c|c|c|c|c|c|c|}
\hline \multirow[t]{2}{*}{ Semantic Relation } & \multicolumn{2}{|c|}{ Related } & \multicolumn{2}{|c|}{ Unrelated } & \multicolumn{2}{|c|}{ Priming effect } \\
\hline & $\mathrm{RT}$ (ms) & $\mathrm{PE}(\%)$ & $\mathrm{RT}(\mathrm{ms})$ & PE (\%) & $\mathrm{RT}(\mathrm{ms})$ & PE $(\%)$ \\
\hline \multicolumn{7}{|l|}{ Associative } \\
\hline L1 & $506(86)$ & 13.55 & $515(75)$ & $16.23(8.11)$ & 9 & 2.68 \\
\hline $\mathrm{L} 2$ & $512(38)$ & $7.20 \quad(5.49)$ & $528(49)$ & $7.06(6.86)$ & 16 & -.14 \\
\hline \multicolumn{7}{|l|}{ Categorical } \\
\hline $\mathrm{L} 1$ & $511(75)$ & $15.47(11.20)$ & $520(83)$ & $14.02(9.95)$ & 9 & -1.45 \\
\hline L2 & 534 (49) & $6.42(4.26)$ & $531(47)$ & 9.89 (7.97) & -3 & 3.47 \\
\hline
\end{tabular}

relation $(F[1,30]=4.55, p<.05)$. Separate analyses by Language revealed a main effect of Semantic relation that approached significance $(F[1,15]=4.03$, $p=.05)$ in the L2 condition. Bilinguals in the L2 condition made more errors responding to unrelated than to related categorical targets $(F[1,15]=6.00$, $p<.05$; associative targets: $F<1$ ). Bilinguals in the L1 condition made approximately the same number of errors for both types of Semantic relation $(F<1)$ and both types of Relatedness $(F<1)$.

In summary, RT data from the L1 condition and the L2 condition did not disclose any differences between the two language conditions. Subjects in the L1 and the L2 condition showed a priming effect (across Semantic relation) and an effect of the factor Semantic relation (across Relatedness). The error data showed that overall subjects in the L1 condition made more errors than subjects in the L2 condition. In addition, subjects in the L2 condition showed a categorical priming effect in the error data. On the other hand, subjects in the L1 condition showed no priming effect in the error data (across Semantic relation).

\section{Electrophysiological data}

Visual inspection of ERPs across groups. In both groups about $8 \%$ of the trials were rejected due to eye blinks, horizontal eye movement or amplifier blocking. The overall morphology of the waveforms in the L1 condition and L2 condition was comparable. Waveforms were characterized by an early anterior/central negativity (anterior N1) with a peak latency around $120 \mathrm{~ms}$ and a posterior negativity (posterior N1) around $175 \mathrm{~ms}$. At occipital sites the N1 was preceded by a positivity at approximately 100 ms (P1). The N1 component was followed at most sites by a positivity (P2) around $200 \mathrm{~ms}$. The N1/P2 complex was followed by two late components. There was negative-going wave around $400 \mathrm{~ms}$ (N400) with a broad scalp distribution. The N400 was followed by a positive-going wave with a peak latency around $600 \mathrm{~ms}$ with a posterior distribution (P3 or late positive component). ${ }^{4}$

In the $\mathrm{L} 2$ condition a small N400 effect was most prominent for both semantic relations at temporal/ posterior scalp locations (see Figures 1a and 2a; WL, WR; Pz). At some sites the effect extended into a late time window (500-800 ms). In comparison, the waveforms in the L1 condition showed an earlier onset for associative relations at the anterior and central midline sites (F7, F8, Fz, Cz), while an N400 effect for categorical relations was visible at posterior midline and lateral sites $(\mathrm{O} 1, \mathrm{Pz}$ and $\mathrm{O} 2$; see Figures $1 \mathrm{~b}$ and $2 \mathrm{~b}$ ). The overall distribution of the N400 activity appeared more anterior/anterior temporal for associative relations and more temporal/posterior for categorical relations across scalp sites. This differentiation extended into a later time window.

150-300 ms. An ANOVA of mean amplitudes during this epoch revealed that the overall waveforms in the two language conditions were comparable (midline: $F<1$ ); lateral: $F<1$ ). No main effects of Semantic relation nor Relatedness were found $(F<1)$. Language did not interact with Semantic relation (midline: $F[1,30]=1.74, p>.05$; lateral: $F<1$ ) nor Relatedness (midline: $F[1,30]=1.93$, $p>.05$; lateral: $F[1,30]=2.06, p>.05)$. However, there was an interaction between Semantic relation, Relatedness and Electrode-Site (midline: $F[2,60]=$ 5.82, $p<.05$; lateral: $F[4,120]=5.46, p<.05)$. The interaction between Relatedness and Electrode-Site was significant in the associative condition (midline: $F[2,60]=6.02, p<.01$; lateral: $F[4,120]=4.37$,

\footnotetext{
${ }^{4}$ It should be noted that it is standard procedure in ERP reports to describe the morphology and distribution of the waveforms by visual inspection and more specifically by critical condition (here Language). Of course, interpretations of modulations and distributional effects are only discussed based on statistical results (normalized data).
} 
$p<.05)$, but not in the categorical condition (midline: $p>.05$; lateral: $p>.05$ ).

In summary, the analyses of the early time window revealed a pronounced $\mathrm{P} 2$ effect in the associative condition across both language conditions.

300-550 ms. The mean amplitude of the N400 between languages did not differ (midline: $F<1$; lateral: $F<1$ ). No main effect of Semantic relation was found $(F<1)$. The main effect of Relatedness approached significance at lateral sites (midline: $F[1,30]=3.13, p>.05$; lateral: $F[1,30]=3.76$, $p>$.05). The interactions between Language and Semantic relation and Language and Relatedness were not significant (midline and lateral: $F<1$ ). However, there was a three-way interaction of Semantic relation, Relatedness and Electrode-Site (midline: $F[2,60]=10.21, p<.01$; lateral: $F[4,120]=$ $6.25, p<.01)$. This three-way interaction was not qualified by Language (midline: $p>.05$; lateral: $p>.05)$. Associative priming was found for midline and lateral sites (midline: $F[2,60]=5.74, p<.01$; lateral: $F[4,120]=6.61, p<.01)$. Overall, the mean amplitude associated with unrelated categorical targets was more negative-going than was the mean amplitude of related categorical targets $(F[1,30]$ $=4.91, p<.05)$. This effect also interacted with Electrode-Site (midline: $F[2,60]=5.95, p<.01$; lateral: $F[4,120]=6.61, p<.01)$. These results indicate that there is an associative and categorical N400 priming effect that did not vary as a function of language. 5

550-800 $\mathrm{ms}$. The mean amplitude did not differ between Language (midline and lateral: $F<1$ ), and did not vary as a function of Semantic relation (midline and lateral: $F<1$ ) nor Relatedness (midline and lateral: $F<1$ ). However, there was an interaction between Semantic relation, Relatedness and Electrode-Site (midline: $F[2,60]=5.31, p<.05$; lateral: $F[4,120]=5.87, \mathrm{p}<05)$. While there was a significant interaction of Relatedness and Electrode-

\footnotetext{
5 The use of a rather conservative N400 time window (300-550 $\mathrm{ms}$ ) was motivated by the previous use of this time window in both monolingual and bilingual word pair and single presentation priming studies. Granted that the priming effect in the traditional $\mathrm{N} 400$ window was marginal we also administered a time sequence analysis (100-900 ms, steps: $100 \mathrm{~ms})$ on the difference waves, which are calculated by subtracting the mean amplitude values of the related condition from the unrelated condition. This allowed a direct comparison of the associative and categorical N400 priming effects in an omnibus analysis (between Language). Statistically significant results were found in an interaction between Semantic relation by Electrode-Site (normalized) in all time-step windows at midline and lateral sites. The data confirm that the traditional time window analyses covered the relevant priming effects for both semantic relation types.
}

Site in the associative condition (midline: $F[2,60]=$ 7.34, $p<.01$; lateral: $F[4,120]=6.14, p<.01)$, the same interaction only approached significance in the categorical condition (midline: $p>.05$; lateral: $F[4,120]=2.87, p>.05)$. Again, this three-way interaction did not vary as a function of Language $(F<1)$. The results of the late time window show significant associative priming effects which were comparable in the $\mathrm{L} 1$ condition and the L2 condition.

In summary, the ERP data revealed no differences between the L1 and the L 2 conditions. Results from the early time window displayed differences between associative and categorical relations in the $\mathrm{P} 2$ region. While the N400 priming effect was marginally significant across the factor Semantic relation, the threeway interaction of Relatedness, Semantic relation and Electrode-Site revealed both associative and categorical priming. This effect extended into the late time window (P3 region), but was only significant for associative priming.

\section{Discussion}

The aim of the current RT/ERP study was to provide further evidence about the nature of lexical-semantic processes during bilingual word recognition. Based on the predictions of the revised hierarchical model (e.g., Kroll and Stewart, 1990, 1994) it was expected that if connections between L1 and the conceptual level of representation are stronger than for L2 then there should be weaker RT and ERP priming effects in L2 than in L1. In order to evaluate the validity of the asymmetry hypothesis we tested early fluent bilinguals rather than late fluent bilinguals. It should be noted though, that while we did not directly compare early and late fluent bilinguals there is evidence supporting the fact that language dominance and equal fluency in L1 and L2 can modulate language asymmetry (e.g., Heredia, 1997; Kotz, 1996). By controlling parameters such as fluency and literacy fluency which have been critically correlated with the relative size of the L1 and L2 lexicon, it was predicted that RT/ERP priming should be symmetrical (size of language lexicon hypothesis, e.g., Kroll, 1993). Furthermore, the single word presentation LDT (Kotz, 1998; Kotz and Holcomb, 1996; Shelton and Martin, 1992) was used to test semantic priming under decreased controlled processing conditions and to evaluate possible differential priming effects as a function of the respective sensitivities of RT and ERP measures.

Comparisons of L1 and L2 data revealed symmetrical associative RT priming and symmetrical associative and categorical ERP priming. These data indicate that the use of the single word presentation 

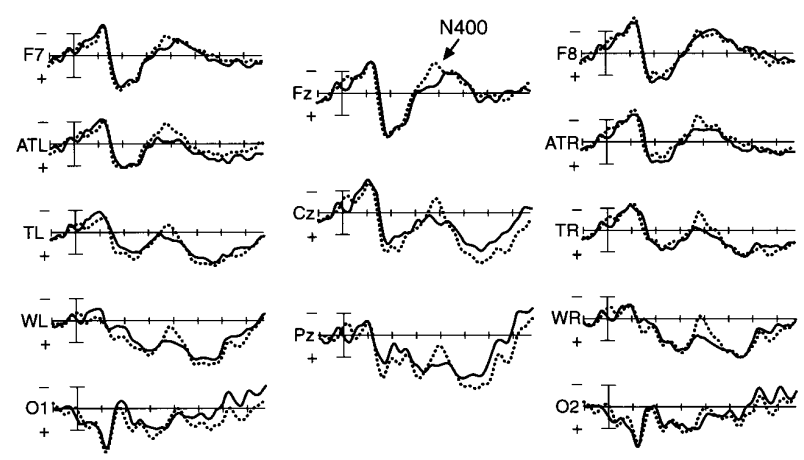

(a)

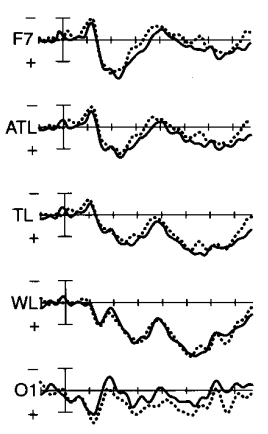

(b)
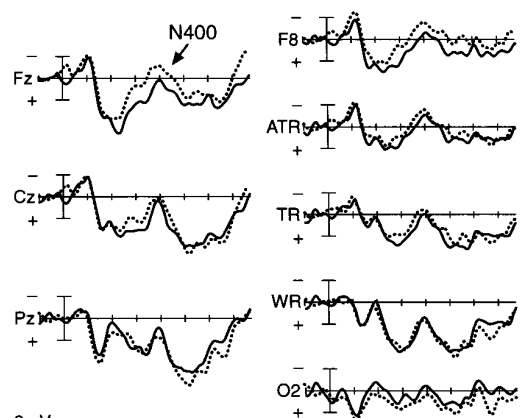

$-2 \mu V_{T}$

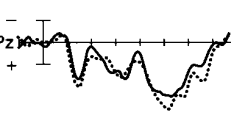

$300+600$

— RELATED TARGETS _.... UNRELATED TARgETS

Figure 1. L2 (a) and L1 (b) condition - ERPs elicited by critical targets in the associative condition in the single word presentation LDT. Waveforms show the average for related and unrelated target conditions from $100 \mathrm{~ms}$ prior to the target onset up to $800 \mathrm{~ms}$.

LDT in early fluent bilinguals leads to results comparable to those for monolingual speakers of English, namely, differential priming effects in RTs and ERPs.

$R T$ language asymmetry. The symmetrical $\mathrm{RT}$ priming effects in L1 and L2 did not confirm language asymmetry as proposed by Kroll and Stewart (1990, 1994) for L2 acquisition. Rather, these data suggest that when language fluency and literacy fluency in L1 and L2 are comparable and task parameters are controlled, the activation of conceptual representations in L1 and L2 is symmetrical. Granted that the proportion of related targets was low and that the recognition of a relation between prime and target words was prevented by presenting words in a list, it is unlikely that subjects were able to predict the target from the prime (e.g., Altarriba, 1990, 1991; Keatley and De Gelder, 1992; Keatley et al., 1994). However, final confirmation of this interpretation should come from a direct comparison of early fluent bilinguals with late fluent bilinguals in the single word presentation LDT.

$R T$ semantic relation asymmetry. Minimizing the

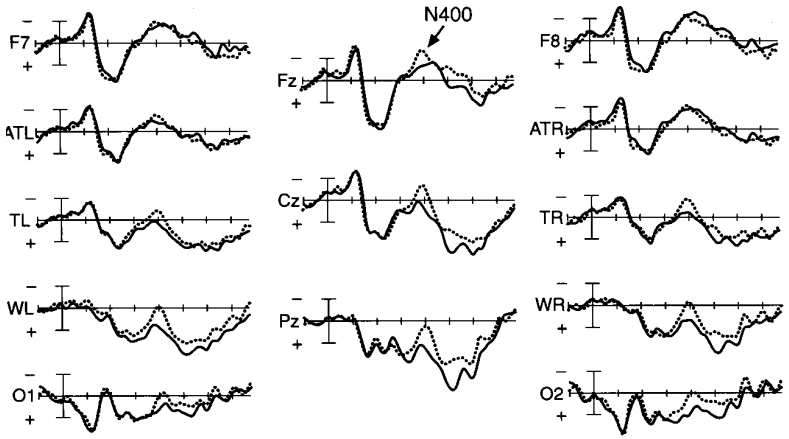

(a)
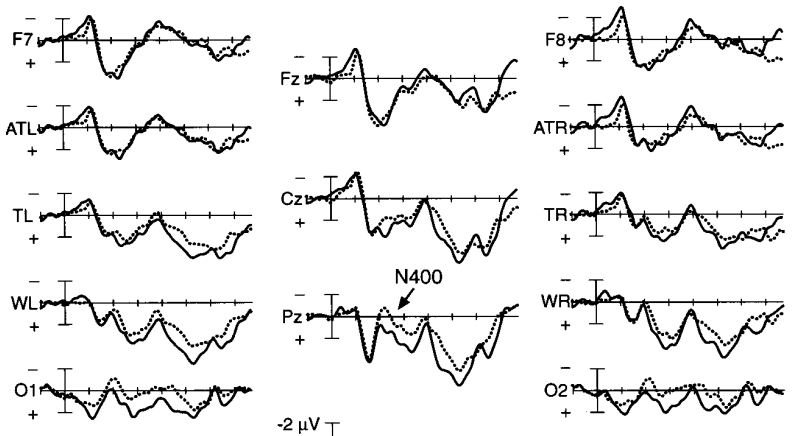

(b)
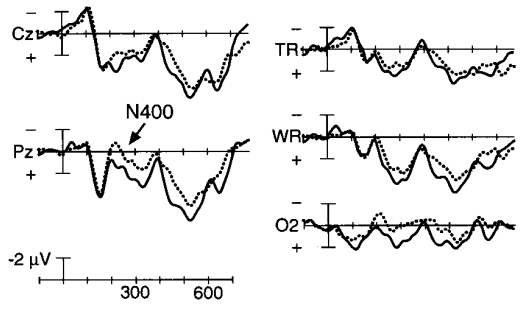

— RELATED tARgets .... UnRELATED taRgets

Figure 2. L2 (a) and L1 (b) condition - ERPs elicited by critical targets in the categorical condition in the single word presentation LDT. Waveforms show the average for related and unrelated target conditions from $100 \mathrm{~ms}$ prior to the target onset up to $800 \mathrm{~ms}$.

controlled processing of prime/target pairs in the single word presentation LDT resulted in symmetrical associative priming, but no categorical priming. As these results are comparable with other RT data (e.g., Moss et al., 1995; Shelton and Martin, 1992) one could argue that these data are consistent with the interpretation that associative priming reflects automatic processing. However, as discussed in the monolingual experiment (e.g., Kotz and Holcomb, 1996) the question remains whether the differential RT priming effect is the result of categorical priming being more variable and thus resulting in a smaller or non-significant RT effect (e.g., Dagenbach et al., 1990; Shelton and Martin, 1992). Furthermore, it has also been argued by McRae and colleagues (McRae and Boisvert, 1998) that when item similarity is controlled, categorical priming can occur in the single word presentation LDT. However, there is evidence that associative and categorical priming run a different time-course of activation during word recognition (see RT and ERP timing differences, Koivisto, 1998; Kotz and Holcomb, 1996; Kotz, 1998). In particular, Kotz (1998) has argued that 
significant time-course differences between associative and categorical relations correlate with the relative word frequency of the primes rather than the word frequency of the targets, as the prime word frequency of associative primes is normally higher than the prime word frequency of categorical primes. Closer inspection of response latencies in the two semantic relation conditions support such an interpretation. Overall, the response latencies for associative relations were faster than the response latencies for categorical relations in both language conditions. In addition, the slightly higher semantic relatedness rating for associative relations than categorical relations could also have contributed to this effect. In conclusion, while parameters such as similarity and time-course need to be further investigated, the current data provide further evidence for associative RT priming but no categorical priming in the single word presentation LDT (e.g., Shelton and Martin, 1992) also in a bilingual population.

Percentage error language asymmetry. The single word presentation LDT required subjects to respond rapidly to a sequence of primes, targets and pseudowords. If bilinguals access words from either language at a slower rate, then the activation of both prime and target words might be delayed or more error prone. What needs to be explained is why error rates were higher in L1 than L2. Heredia (1997) reported that early bilinguals might show differential language sensitivities towards their dominant language in comparison to late bilinguals. Adapting this interpretation to our results one could argue that literacy ratings in L1 and L2 should have critically influenced the current results as the task involved speeded reading of words. Literacy ratings of the participants confirmed an L2 dominance for reading. Thus, if English was predominantly the functional language (i.e., in school for reading, studying and writing) and Spanish was used for communication in informal settings, then language dominance should vary as a function of modality (i.e., visual vs. auditory). In summary, the current RT data support the view that L2 fluency modulates language asymmetry.

ERP asymmetries. The current data provide evidence that the N400 latency as a marker of language fluency was equivalent in the both L1 and L2. ${ }^{6}$ Furthermore, as in the RT data critical language comparisons in the ERPs were not significantly dif-

\footnotetext{
${ }^{6}$ In a direct comparison of the monolingual and bilingual data we found evidence for RT latency differences but N400 peak latency compatibility between the three groups. This does not confirm the conclusion that delayed RTs might correlate with a delayed latency of the N400 effect (e.g., Ardal et al., 1990; Kutas et al., 1993). This indeed might only be the case when bilinguals are not equally fluent in both L1 and L2 (see Kotz, 1996).
}

ferent. There were comparable associative and categorical N400 priming effects in both language conditions. Thus, equivalent ERP priming effects in L1 and L2 suggest that fluent bilinguals can directly access conceptual representations in L1 and L2 without rerouting the access of word meaning in L2 via L1. However, the fact that we also found differential priming effects in the RT but not in the ERP data in a bilingual population leaves open the question of whether these results provide evidence that RTs and ERPs monitor different cognitive processes (i.e., automatic and/or controlled processes) or show different sensitivities towards differential semantic priming effects (e.g., Kotz, 1998)

Taken together, the current RT and ERP data do not confirm the asymmetry hypothesis derived from revised hierarchical model (e.g., Kroll and Stewart, 1990, 1994) as symmetrical priming was found in L1 and L2. These conclusions foster an interpretation of asymmetry that might vary as a function of early acquisition of two languages and/or language dominance (see Heredia, 1997).

\section{References}

Algarbal, S., Ruiz, J.C. \& Sanmartin, J. (1988). The University of Valencia's computerized word pool. Behavior Research Methods, Instruments, and Computers, 20, 398-403.

Altarriba, J. (1990). Constraints on interlingual effects in priming in Spanish English bilinguals. Dissertation, Vanderbilt University.

Altarriba, J. (1991). Is there automatic semantic priming across a bilinguals's two languages? Paper presented at the meeting of the American Psychological Society, Washington, DC.

Anderson, J. E. \& Holcomb, J. P. (1995). Auditory and visual semantic priming using different stimulus onset asynchronies: an event-related brain potential study. Psychophysiology, 32, 177-190.

Ardal, S., Donald, M. W, Meuter, R., Muldrew, S. \& Luce, M. (1990). Brain responses to semantic incongruity in bilinguals. Brain and Language, 39, 187-205.

Beauvillain, C. \& Grainger, J. (1988). Accessing interlexical homographs: some limitations of the language-selective access. Journal of Memory and Language, 26, 658-672.

Becker, C. A. (1979). Semantic context and word frequency effects in visual word recognition. Journal of Experimental Psychology: Human Perception and Performance, 5, 252-259.

Becker, C. A. (1980). Semantic context effects in visual word recognition: an analysis of semantic strategies. Memory and Cognition, 8, 493-512.

Besson, M., Kutas, M. \& Van Petten, C. (1992). An eventrelated potential (ERP) analysis of semantic congruity and repetition effects in sentences. Journal of Cognitive Neuroscience, 4, 132-149.

Boddy, J. (1986). Event-related potentials in chronometric 
analysis and primed word recognition with different stimulus onset asynchronies. Psychophysiology, 23, 232-245.

Brown, C. M. \& Hagoort, P. (1993). The processing nature of the N400: evidence from masked priming. Journal of Cognitive Neuroscience, 5, 34-44.

Chen, H-C. \& Ng, M-L. (1989). Semantic facilitation and translation priming effects in Chinese-English bilinguals. Memory and Cognition, 17, 454-462.

Chwilla, D. J., Brown, P. \& Hagoort, P. (1995). The N400 as a function of the level of processing. Psychophysiology, 32, 274-285.

Chwilla, D. J., Kolk, H. J. \& Mulder, G. (2000). Mediated priming in the lexical decision task: evidence from event-related potentials and reaction times. Journal of Memory and Language, 42, 314-341.

Dagenbach, D., Horst, S. \& Carr, T. H. (1990). Adding new information to semantic memory: how much learning is enough to produce automatic priming? Journal of Experimental Psychology: Learning, Memory and Cognition, 16 (4), 581-591.

Deacon, D., Hewitt, S., Yang, C.-M. \& Nagata, M. (2000). Event-related potentials indices of semantic priming using masked and unmasked words: evidence that the N400 does not reflect a post-lexical process. Cognitive Brain Research, 9, 137-146.

De Groot, A. M. B. (1984). Primed lexical decision: combined effects of the proportion of related prime-target pairs and the stimulus onset asynchrony of prime and target. Quarterly Journal of Experimental Psychology, 36A, 253-280.

De Groot, A. M. B. (1992). Determinants of word translation. Journal of Experimental Psychology: Learning, Memory, and Cognition, 18, 1001-1018.

De Groot, A. M. B. \& Nas, G. L. J. (1991). Lexical representation of cognates and noncognates in compound bilinguals. Journal of Memory and Language, 30, 90-123.

Den Heyer, K., Briand, K. \& Dannenbring, G. L. (1983). Strategic effects in a lexical decision task: evidence for automatic and attention-driven processes. Memory and Cognition, 11, 374-381.

Durgunoglu, A. Y. \& Roediger, H. L., III (1987). Test differences in accessing bilingual memory. Journal of Memory and Language, 26, 377-391.

Forster, K. (1979). Levels of processing and the structure of the language processor. In W. E. Cooper \& E. C. T. Walker (eds.), Sentence processing: psycholinguistic studies presented to Merrill Garett, pp. 27-85. Cambridge, MA: MIT Press.

Frenck-Mestre, C. \& Prince, P. (1997). Second Language autonomy. Journal of Memory and Language, 37, 481-501.

Frenck-Mestre, C. \& Pynte, J. (1987). Semantic representation and surface forms: a look at across-language priming in bilinguals. Journal of Psycholinguistic Research, 16 (4), 383-296.

Geisser, S. \& Greenhouse, S. W. (1959). On methods in the analysis of profile data. Psychometrika, 24, 95-112.

Gerard, L. \& Scarborough, D. (1989). Language-specific lexical access of homographs by bilinguals. Journal of Experimental Psychology: Learning, Memory and Cognition, 15, 305-315.

Harper Collins. (1990). Spanish Dictionary. New York: Harper Collins.

Heredia, R. (1997). Bilingual memory and hierarchical models: a case for language dominance. Current Directions in Psychological Science, 6, 34-39.

Holcomb, P. J. (1986). Electrophysiological correlates of semantic facilitation. Electroencephalography and Clinical Neurophysiology, 38, 320-322.

Holcomb, P. J. (1988). Automatic and attentional processing: an event-related brain potential analysis of semantic priming. Brain and Language, 35, 66-85.

Holcomb, P. J. (1993). Semantic priming and stimulus degradation: implications for the role of the N400 in language processing. Psychophysiology, 30, 47-61.

Holcomb, P. J. \& Neville, H. J. (1990). Semantic priming in visual and auditory lexical decision: a between modality comparison. Language and Cognitive Processes, 5, 281-312.

Holcomb, P. J. \& Neville, H. J. (1991). The electrophysiology of spoken sentence processing. Psychobiology, 19, 286-300.

Jasper, H. H. (1958). Report to the committee on methods of clinical examination in electroencephalography Appendix: the ten-twenty system of the International Federation. Electroencephalography and Clinical Neurophysiology, 10, 371-375.

Jin, Y-S. (1990). Effects of concreteness on cross-language priming of lexical decision. Perceptual and Motor Skills, 70, 1139-1154.

Johnson, R. J. (1993). On the neuronal generators of the P300 component of the event-related potential. Psychophysiology, 30, 90-97.

Juilland, A. \& Chang-Rodriguez, E. (1964). Frequency dictionary of Spanish words. The Netherlands: Mouton.

Keatley, C. W. \& De Gelder, B. (1992). The bilingual primed lexical decision task: cross-language priming disappears with speeded responses. European Journal of Cognitive Psychology, 4, 273-292.

Keatley, C. W., Spinks, J. A. \& De Gelder, B. (1994). Asymmetrical cross-language priming effects. Memory and Cognition, 22, 70-84.

Kirsner, K., Smith, M., Lockhart, R., King, M. \& Jain, M. (1984). The bilingual lexicon: language specific units in an integrated network. Journal of Verbal Learning and Verbal Behavior, 23, 519-539.

Koivisto, M. (1998). Categorical priming in the cerebral hemispheres: automatic in the left hemisphere, postlexical in the right hemisphere? Neuropsychologia, 36, $661-668$.

Kotz, S. A. (1996). Bilingual memory revisited: an electrophysiological investigation of lexical and semantic representations in fluent bilinguals. Dissertation, Tufts University.

Kotz, S. A. (1998). Comparing the auditory and visual sequential priming paradigm: an event-related potential study. Journal of Cognitive Neuroscience Supplement, 54. 
Kotz, S. A. \& Holcomb, P. J. (1996). An event-related potential investigation of the sequential priming paradigm. Cognitive Neuroscience Third Annual Meeting, San Francisco.

Kroll, J. F. (1993). Accessing conceptual representations. In R. Schreuder \& B. Weltens (eds.), The bilingual lexicon, pp. 53-83. Amsterdam/Philadelphia: John Benjamins.

Kroll, J. F., Sholl, A., Altarriba, J., Luppino, C., Moynihan, L. \& Sanders, C. (1992). Cross-language semantic priming: evidence for independent lexical and conceptual contributions. Manuscript, Mount Holyoke College, South Hadley, MA.

Kroll, J. F. \& Stewart, E. (1990). Concept mediation in bilingual translation. Paper presented at the 31st Annual Meeting of the Psychonomic Society, New Orleans.

Kroll, J. F. \& Stewart, E. (1994). Category interference in translation and picture naming: evidence for asymmetric connections between bilingual memory representations. Journal of Memory and Language, 33, 149-174.

Kucera, H. \& Francis, W. N. (1967). A computational analysis of present-day American English. Providence, RI: Brown University Press.

Kutas, M. \& Kluender, R. (1993). What is who violating? A reconsideration of linguistic violations in light of event-related brain potentials. In H. J. Heinze, T. F. Munte \& G. R. Mangun (eds.), Cognitive electrophysiology: basic and clinical applications, $\mathrm{pp}$. 183-210. Boston: Birkauser.

Kutas, M., McCarthy, G. \& Donchin, E. (1979). Augmenting mental chronometry: the P300 as a measure of stimulus evaluation time. Science, 197, 792-795.

Larsen, J. D., Fritsch, T. \& Grava, S. (1994). A semantic priming test of bilingual language storage and compound versus coordinate bilingual distinction with Latvian-English bilinguals. Perceptual and Motor Skills, 79, 459-466.

Lupker, S. J. (1984). Semantic priming without association: a second look. Journal of Verbal Learning and Verbal Behavior, 23, 709-733.

McCarthy, G. \& Wood, C. C. (1985). Scalp distribution of event-related potentials: an ambiguity associated with analysis of variance models. Electroencephalography and Clinical Neurophysiology, 62, 203-208.

McRae, K. \& Boisvert, S. (1998). Automatic semantic similarity priming. Journal of Experimental Psychology: Learning, Memory and Cognition, 24 (3), $558-572$.

Meyer, D. E. \& Ruddy, M. G. (1974). Bilingual wordrecognition: organization and retrieval of alternative lexical codes. Paper presented at the meeting of the Eastern Psychological association, Philadephia.

Meyer, D. E. \& Schvaneveldt, R. W. (1971). Facilitation in recognizing pairs of words: evidence of a dependence between retrieval operations. Journal of Experimental Psychology, 90, 227-234.

Moss, H. E., Ostrin, R. K., Tyler, L. K. \& Marslen-Wilson, W. D. (1995). Accessing different types of lexical semantic information: evidence from priming. Journal of Experimental Psychology: Learning, Memory and Cognition, 21 (4), 863-883.

Neely, J. H. (1991). Semantic priming effects in visual word recognition: a selective review of current findings and theories. In D. Besner \& G. W. Humphreys (eds.), Basic processes in reading: visual word recognition, pp. 264-337. Hillsdale, NJ: Lawrence Erlbaum.

Perea, M. \& Carreiras, M. (1998). Effects of syllable frequency and neighborhood frequency in visual word recognition. Journal of Experimental Psychology: Human Perception and Performance, 24 (1), 134-144.

Postman, L. \& Keppel, G. (1970). Norms of word associations. New York: Academic Press.

Potter, M. C., So, K-F., Von Eckhardt, B. \& Feldman, L. B. (1984). Lexical and conceptual representation in beginning and proficient bilinguals. Journal of Verbal Learning and Verbal Behavior, 23, 23-28.

Scarborough, D., Gerard, L. \& Cortese, C. (1984). Independence of lexical access in bilingual word recognition. Journal of Verbal Learning and Verbal Behavior, 23, 84-99.

Schwanenflugel, P. \& Rey, M. (1986). Interlingual semantic facilitation: evidence for a common representational system in the bilingual lexicon. Journal of Memory and Language, 25, 605-618.

Shelton, J. R. \& Martin, R. C. (1992). How semantic is automatic semantic priming? Journal of Experimental Psychology: Learning, Memory and Cognition, 18, 1191-1210.

Snodgrass, J. G. (1984). Concepts and their surface representations. Journal of Verbal Learning and Verbal Behavior, 23, 3-22.

Snodgrass, J. G. (1993). Translating vs. picture naming: similarities and differences. In R. Schreuder \& B. Weltens (eds.), The bilingual lexicon, pp. 83-114. Amsterdam/Philadelphia: John Benjamins.

Tzelgov, J. \& Eben-Ezra, S. (1992). Components of the between-language semantic priming effect. European Journal of Cognitive Psychology, 4, 253-272.

Tzelgov, J. \& Henik, A. (1989). The insensitivity of the semantic relatedness effect to surface differences and its implications. Paper presented at the First European Congress of Psychology, Amsterdam.

Van Petten, C. \& Kutas, M. (1990). Interactions between sentence context and word frequency in event-related brain potentials. Memory and Cognition, 18, 380-393.

Weber-Fox, C. M. \& Neville, H. J. (1996). Maturational constraints on functional specializations for language processing: ERP and Behavioral evidence in bilingual speakers. Journal of Cognitive Neuroscience, 8 (3), 231-256.

Williams, J. N. (1994). The relationship between word meanings in the first and second language: evidence for a common, but restricted, semantic code. European Journal of Cognitive Psychology, 6, 195-220.

Received December 13, 1999 Revision accepted February 8, 2001 